\title{
Consideraçóes sobre uso e Norma na Gramática Portuguesa - O Methodo Grammatical para todas as Linguas (1619), de Amaro de Roboredo
}

\author{
Considerations on Norm and use of Portuguese \\ Grammar in The Seventeenth Century - Amaro de \\ Roboredo's Methodo Grammatical \\ para todas as Linguas (1619)
}

Marli Quadros Leite ${ }^{1}$

\begin{abstract}
RESUMO: Nosso objetivo neste trabalho é mostrar como, em um manual de ensino de línguas, intitulado Methodo grammatical para todas as linguas, publicado em 1619, Amaro de Roboredo ,registrou aspectos do uso e da norma do português. Esta pesquisa se inscreve no campo da epistemologia e da historiografia linguística (Auroux 2007), especificamente no que concerne à reconstrução da história dos saberes linguísticos, no âmbito da gramaticografia portuguesa. Para desenvolvimento desses temas, este artigo se subdivide em três partes: primeiro, há a inserção do autor e de sua obra em seu tempo, colocando-o frente às ideias linguísticas em vigor; isso nos leva à segunda parte, em que se discute a apresentação e concepção do Methodo, assim como suas causas e consequências (tardias) e tudo o que isso implicou para o ensino do português; a terceira e última parte traz o estudo sobre o registro do uso e da norma do português, no rastro da exposição das regras para o ensino do latim. A pesquisa nos leva à conclusão de que Roboredo, mesmo sem o objetivo de descrever ou normalizar a língua portuguesa, deixou, em seu método para ensino de línguas, registros importantes sobre peculiaridades de uso e norma dessa língua, especialmente na parte reservada ao "curioso português", ou seja, em um subcapítulo dirigido àquele que, além de estudar o latim, tem interesse em conhecer as regras da língua vernácula que então se gramatizava.
\end{abstract}

Palavras-chave: Norma; uso; história da gramática; língua portuguesa; historiografia.

1 Universidade de São Paulo/CNPq. E-mail: mqleite@usp.br 


\begin{abstract}
With this paper, we aim to show how Amaro de Roboredo's language teaching manual, Methodo grammatical para todas as línguas [Grammar Method for all Languages], published in 1619, recorded aspects of Portuguese norm and use. This research is situated in the fields of epistemology and linguistic historiography (Auroux 2007), specifically in terms of the historical reconstruction of linguistic knowledge, within the realm of Portuguese grammar studies. In order to carry out the investigation of these themes, this paper is divided into three sections: firstly, it places the author and his work into the context of the time period in order to understand the text, i.e., we look at the linguistic ideas of the time. This leads us to the second section of the paper, in which the concept of the Method is presented and discussed - as well as its causes and (late) consequences, and the effect that they had on the teaching of the Portuguese language. The third and final section of the study refers to the record of Portuguese use and norm following the steps used for teaching Latin rules. The research leads us to the conclusion that despite the fact that Roboredo did not set out to describe or normalize the Portuguese language, his method is an important legacy of records of specific features in the uses and norms for this language, especially where he addresses the "curious Portuguese person", i.e., a subchapter addressed to readers who, besides studying Latin, were interested in becoming acquainted with the rules of the vernacular language in the process of being grammaticized at the time.
\end{abstract}

Keywords: Norm, use, history of grammar, Portuguese language, historiography.

\title{
CONSIDERAÇÕES INICIAIS
}

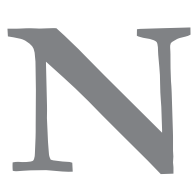

osso objetivo neste trabalho é mostrar como, em um manual de ensino de línguas, intitulado Methodo grammatical para todas as línguas, publicado em 1619, Amaro de Roboredo registrou aspectos do uso e da norma do português. ${ }^{2} \mathrm{O}$ alvo do autor não era a descrição ou o ensino da língua portuguesa, mas o ensino do latim, ou de outras línguas, por meio da metalinguagem do português (ou de outra língua materna que permitisse ao aluno estudar o latim). Isso indica que, mesmo bem antes da publicação da Grammaire Générale e Raisonée de Port Royal, de 1660, Roboredo tratou da universalidade das regras da gramática, tomando como parâmetro para a comparação as regras da língua materna do estudante e como alvo o latim, para mostrar a existência de regras universais, existentes no latim e em outras línguas como o português, o italiano, o espanhol e o francês, essas citadas textualmente. Além desse, o livro tem outro objetivo, muito claro, voltado à crítica ao método jesuítico de ensino, que se praticava na Europa

2 Para a discussão sobre os conceitos de uso e de norma linguísticos, remetemos o leitor a Leite (2007). 
naquele tempo. A obra representa uma resistência à metodologia de ensino de latim, pela explicitação de razões por que o método tradicional de ensino dessa língua, isto é o ensino do latim pelo latim, sendo essa uma língua morta e, também, não tendo o aprendiz outra experiência de estudo de gramática, ${ }^{3}$ não mais atingia o objetivo de levar o aluno ao domínio da língua. Era preciso que o estudante conhecesse as regras de sua língua e, por meio dessas, que eram, em certa medida, as mesmas do latim, dominaria as do latim. ${ }^{4}$

Amaro de Roboredo mais que um gramático e professor de latim deve ser considerado um teórico da área de ensino de línguas estrangeiras, e o Methodo grammatical para todas as linguas comprova essa afirmação. No contexto do século XVII, revelou-se um homem inovador no domínio do ensino de línguas estrangeiras, não somente por ter proposto um revolução no ensino do latim, no que concerne tanto à seleção dos assuntos que devia constar dos manuais de ensino dessa língua e ao ensino bilíngue, ${ }^{5}$ a partir da língua materna, quanto à defesa do universalismo de certas regras da gramática. O universalismo das regras, pois, é a tese a partir da qual o autor constrói o seu Methodo. O Autor não se detém, contudo, na explicação da natureza e formação das regras universais, embora, por meio de alguns comentários feitos, seja possível inferir que essas se consolidam pela tradição do uso. Portanto, os exemplos do Methodo são de frases comuns, consideradas de fácil compreensão, para que o aluno possa com mais facilidade compreender a gramática da língua e o sentido das frases que lê.

O método, pois, se constrói na base do estudo de frases advindas de duas fontes: frases construídas com base em palavras recolhidas do Janua Linguarum ${ }^{6}$

3 Lembre-se aqui que o português não era, àquela altura, objeto de estudos nas escolas. Quando muito, os filhos de pessoas abastadas tinham aulas particulares de gramática portuguesa. Na escola estudava-se o latim, pela gramática do Pe. Manuel Álvares, sobre a qual se falará em seguida.

4 Sobre esse método de ensino baseado na tradução, cf. Leite (2010).

5 Como afirmam Assunção; Fernandes; León e (2007), houve, antes de Roboredo, um gramático português Pedro Sanchez que escreveu, em português, em (1610), a Arte de grammatica, pêra em breve se saber latim: composta em lingoagem, e verso portugues. Com bum breve vocabulário no cabo e algumas phrases latinas. Lisboa: Officina de Vicente Alvares). Essa obra, todavia, não tem o mesmo caráter da de Roboredo.

6 O Janua Linguarum sive Modus maxime accomodatus, quo patefit aditus ad omnes linguas intelligendas foi um método de ensino de línguas, criado e publicado em 1611, pelos padres jesuítas da 
e frases retiradas de livros, cuja autoria não é indicada ("Algũa sentenças teem boa moralidade tiradas de vários Autores; outras seria possivel melhor frase sem repetição de palavras.’')

Uma análise atenta do Methodo revela que Roboredo constrói, a partir da ideia da universalização das regras das línguas, uma teoria e um método para o ensino de línguas, cujo princípio é a tradução, em duplo sentido: primeiro, da língua materna para a latina e, segundo, da latina para a materna. Para que isso seja viável à aprendizagem, o manual traz uma seleção de temas que o Autor entende essenciais ao ensino e à aprendizagem de línguas. Essa seleção se traduz em uma redução de temas que diz respeito tanto à eleição de alguns assuntos da gramática da língua materna quanto da estrangeira e à rejeição de outros tantos assuntos considerados supérfluos. ${ }^{7}$

Essa economia temática o leva à divisão de sua gramática em três partes - gramática, cópia e frase: na primeira apresenta a síntese de uma teoria gramatical fundada em cinco pontos explicados morfossintaticamente; na segunda traz as mil e duzentas frases para estudo das palavras e sintaxe latina e portuguesa, por meio de tradução e comparação que o próprio aluno deve fazer; na terceira expõe mais cento e oitenta e sete frases, dessa vez já traduzidas, em latim e português, e postas lado a lado, para que o aluno possa comparar a sintaxe das duas línguas, com relevo para o uso das preposições que regem os verbos das duas línguas.

Para desenvolvimento desses temas, este artigo se subdivide em três partes: primeiro, há a inserção do autor e de sua obra em seu tempo, colocando-o frente às ideias linguísticas em vigor; isso nos leva à segunda parte

Companhia dos Irlandeses de Salamanca. O método consiste na apresentação, por temas, de 1142 frases latinas acompanhadas da tradução para o espanhol. O método foi traduzido para várias línguas, inclusive para o Português, por Roboredo, que fez não somente uma tradução, mas uma adaptação da obra, em 1623, cujo título é Porta de línguas, ou modo muito acommodado para as entender publicado primeiro com a tradução espanhola, agora acrescentado a portuguesa com números interliniais, pelos quaes possa entender sem mestre estas linguas o que as não sabe, com as raizes da Latina mostradas em hum compendio do Calepino, ou por melhor do Tesauro, para os que a querem aprender, e ensinar brevemente; e para os estrangeiros que desejão a Portuguesa, e Espanhola. Foi, todavia, pela tradução do tcheco John Amos Comenius, autor de obras didáticas, que o método alcançou seu apogeu e decadência. (Cf. Fernandes, 2005)

7 Esse é um aspecto que conecta Roboredo a Sanctius, ou Francisco Sanchez de las Brosas, autor da Minerva (1587) a quem o autor segue e se refere no prefácio. 
que é a discussão sobre a concepção do Methodo e as consequências (tardias) que implicou para o ensino do português; a terceira e última parte traz o estudo sobre o registro do uso e da norma do português, no rastro da exposição das regras para o ensino do latim.

Esta pesquisa se inscreve no campo da epistemologia e da historiografia linguística (Auroux 2007), especificamente no que concerne à reconstrução da história dos saberes linguísticos, no âmbito da gramaticografia portuguesa. ${ }^{8}$

\section{O horizonte de retrospecção de roboredo: alguns dados biobibliográficos}

Alguns dados da biografia de Amaro de Roboredo não são precisos. Diz-se que é oriundo de Algoso (Trás-os-Montes) ou de Viseu, e os que afirmam ser a cidade de Algoso o berço do gramático apóiam-se no fato de ser essa a cidade indicada no frontispício do Methodo grammatical para todas as linguas, obra publicada em vida do autor. Além disso, na carta do autor a D. Gaspar Alvarez, que serve de Prólogo à obra, Roboredo deixa claro que acompanhou a impressão do livro, do que se pode concluir ser correta a informação sobre sua origem. A incerteza sobre seus dados, contudo, nasce da diversidade, ou ausência, de informações fornecidas por seus biógrafos. ${ }^{9}$ Não apenas a naturalidade é incerta, também, suas datas de nascimento e morte o são. Os que defendem ser o autor natural de Viseu o fazem apoiados no fato de ter sido ele padre nessa cidade, embora tivesse sido, também, secretário do Arcebispo de Évora. Profissionalmente, atuou como preceptor de filhos de nobres espanhóis e portugueses, dentre os quais do primogênito do conde de Castelo Branco. Suas obras são dedicadas aos filhos ou familiares do conde D. Francisco de Castelo Branco, conde de Sabugal. O Methodo é dedicado ao filho primogênito do conde, D. Duarte de Castelo Branco.

O século XVII não foi profícuo em obras gramaticais sobre a língua portuguesa, mas em obras de ortografia dessa língua. ${ }^{10}$ Além disso, conforme

\footnotetext{
8 Este trabalho contém partes da pesquisa de Leite (2010).

9 Cf. Barbosa (1930, p. 125).

10 Algumas outras obras do século XVII são: Leão, Duarte Nunes do (1606). Origem da lingoa portuguesa. Lisboa: Pedro Craesbeeck; Vera, Alvaro Ferreira de (1631). Orthografia ou modo para escrever certo na lingua portuguesa. Lisboa: Mathias Rodrigues; Vera, Alvaro Ferreira de (1631).
} 
Kossarik (2002, p. 8) já chamou a atenção, a produção seiscentista portuguesa ainda não deslocou para si o olhar de linguistas e filólogos. A autora citada, talvez por isso, debruçou-se sobre o Methodo grammatical para todas as linguas, de Amaro de Roboredo, e o reeditou, o que tornou mais fácil o acesso à obra. Mesmo sem ter-se dedicado exclusivamente à gramática portuguesa, Roboredo é considerado o maior gramático da língua portuguesa do século dezessete ${ }^{11}$.

As obras linguísticas de Amaro de Roboredo, publicadas enquanto o autor viveu são as seguintes: ${ }^{12}$

1615 - Regras da ortografia da linguagem portuguesa

1615 - Verdadeira grammatica latina

1619 - Methodo grammatical para todas as linguas

1621 - Raizes da lingua latina

1623 - Porta de linguas

1625 - Grammatica latina, mais breve e facil que as publicadas ate agora

Das Regras da ortografia da linguagem portuguesa não se conhece a obra original do autor, mas uma edição elaborada no século XVIII, pelo Padre Vitorino José da Costa. A Verdadeira grammatica latina era, até bem pouco tempo desaparecida, mas foi reeditada recentemente por pesquisadores portugueses. ${ }^{13}$ A obra As Raizes da lingua latina é um dicionário latino-português-espanhol, em que Roboredo dá especial atenção a problemas de "formação de palavras e a mudanças fonéticas e semânticas que têm lugar nos processos de derivação" (Kossarik, 2002, p. 12). O livro Porta de linguas é uma coletânea de textos latinos, portugueses e espanhóis, acrescida de tratados de teor linguístico, baseada na obra latina Ianua linguarum. ${ }^{14}$ Em sua última obra, Grammatica latina, mais breve

Breves louvores da lingua portuguesa, com notaveis exemplos da muita semelhança, que tem com a lingua latina. Lisboa: Mathias Rodrigues.

11 Cf. Assunção, 1997, p. 205.

12 Cf. Barbosa (op. cit.); Kossarik (op. cit., p. 11); Assunção (1997, p. 206).

13 Cf. Assunção; Léon; Fernandes (2007) que dela encontraram um exemplar único no Fundo Antigo da Universidade de Barcelona e a reeditaram em facsimile.

14 Gonçalves (2005, p. 175) e Gonçalves; Léon; Assunção (2007, XII) apresentam essa obra de Roboredo como uma tradução portuguesa do Ianua linguarum, enquanto Kossarik (2002) 
e facil que as publicadas ate agora, o autor retoma, para explicar, algumas ideias pedagógicas e linguísticas do Methodo grammatical para todas as linguas. ${ }^{15}$

Dentre essas obras, o Methodo é, talvez, a mais conhecida, além de ter sido norteadora de obras importantes do século XVIII, como a de Jeronymo Contador de Argote, Regras da lingua portuguesa, espelho da lingua latina, de 1721, ${ }^{16}$ e da Arte de grammatica portuguesa, de Antonio José dos Reis Lobato. Essa última foi, inclusive, a obra que se tornou, depois das reformas de Pombal, a "gramática oficial" para o ensino da língua portuguesa, ${ }^{17}$ como se comentará adiante.

\section{A concepção do Methodo Grammatical para todas as Linguas: causas e consequências}

\section{O Método Jesuítico}

A Companhia de Jesus, criada em Paris no ano de 1534 e consagrada pela bulla papal Regimini militantis Eclesiae, de 27 de setembro de 1540, foi responsável, também em Portugal, pela organização e condução do ensino. A atuação dos jesuítas no ensino é matéria de muitas discussões e controvérsias, o que não será aqui matéria de estudo. Mesmo dentre seus críticos, todavia, é pacífica a ideia de que a criação da Companhia foi o maior evento pedagógico do século XVI (Cf. Compayré, 1904, p. 162).

A organização da Companhia, que tinha antes do objetivo pedagógico o da catequização, ${ }^{18}$ pautou-se por dois documentos principais: (i) as Constitutions, cujas concepção e redação foram de Inácio de Loyola, o principal idealizador da Companhia, que só vieram a lume três anos depois da morte do fundador,

apresenta-a como obra do autor, baseada na latina.

15 Cf. Kossarik, p. 11-13.

16 A segunda edição dessa obra, vinda à luz em 1725, é a mais comentada por ter sido revista e ampliada pelo autor e, também por trazer um capítulo, o quarto, que constitui importantíssima fonte para estudo da variação do português, pois contém a primeira lição de dialetologia dessa língua.

17 Op. cit., p. 15.

18 A bula do papa dizia “ La Societé est principalement instituée por travailler à l'avancement des âmes dans la vie et dans la doctrine chrétienne. " (Apud Compayré, ibidem.) 
em 1559. ${ }^{19}$ O quarto livro desse documento era dedicado à exposição sobre o método de educação a ser seguido nos colégios dos jesuítas. (ii) O segundo, e mais importante documento educacional jesuítico, pois dedicado à regulamentação dos estudos, foi o Ratio Studiorum, publicado em 1599. Neste documento ficam fixados, minuciosamente

l'ordre et la division des études, l'objet de enseignement dans chaque classe, les devoirs et les fonctions de chaque professeur, le attributions du préfet des études et du recteur qui dirigent chaque maison, et qui correspondent à peu près, le premier au censeur de nos lycées modernes, le second au principal ou au proviseur. (op. cit., p. 168)

O rigor da educação jesuíta é também tema de muitas discordâncias, dentre as quais vale citar aquela havida pelas opiniões diversas de dois de seus grandes alunos: Montaigne e Descartes. Enquanto aquele dizia "que certaines maisons des jesuites ètaient 'des geôles de jeunesse captive", esse rendia elogios aos padres e à educação que lá recebeu. O que é certo, porém, é que os alunos ficavam internos em clausura, muitas vezes impedidos até de receber a visita dos pais, e eram, em certos casos, punidos com chicote (fouet). Para que a Companhia preservasse sua imagem de isenção diante dos castigos, a severidade do chicote não era de responsabilidade dos padres: havia alguém que se encarregava desse serviço, esse era "un correcteur spécial attaché à l'établissement, mais qui ne faisait partie de l'ordre et était chargé d'administrer les châtiments". ${ }^{20}$ A literatura produzida sobre a Companhia deixa ver claramente que a disciplina jesuítica era muito rígida, mas ostentava um discurso de amenidade quanto a esse assunto. A história, contudo, registra fatos de acidentes acontecidos com alguns alunos, em decorrência dos castigos aplicados com excessivo rigor. Compayré, por exemplo, conta uma história que, segundo ele, todos conhecem e foi primeiro contada por Saint-Simon em suas Mémoires: ${ }^{21}$

19 Loyola morreu antes de o documento ficar completamente concluído, por isso a revisão e a apresentação do documento (escrito em latim), foi de responsabilidade do sucessor de Loyola, o Pe. Lainez. Conforme explica Compayré (op. cit.), o principal objetivo das Constitutions era organizar os trabalhos relativos aos noviços, futuros membros da Companhia.

20 Op. cit., p. 175-180.

21 Op. cit, p. 175. Compayré indica em nota que esse acidente ocorreu em 1711 e foi contado por Saint-Simon, IX, p. 83. 
Le fils aîné du marquis de Boufflers avait quatorze ans: il était joli, bien fait, il réussissait à mervelille, il promettait toutes choses. Il était pensionnaire aux jésuites avec eux. Les pères voulerent montrer qu'ils ne craignaient et ne considéraient personne et fouettèrent le petit garçon, parce qu'en effet ils n'avaient rien à craindre du maréchal de Boufflers; mais ils se gardèrent bien d'en faire autant aux deux autres, quoique également coupables, parce qu'ils avaient à compter tous les jours avec Angerson, lieutenant de police. Le petit Boufflers fut saisi d'un tel désespoir qu'il en tomba malade le jour même. En quatre jours cela fut fini... Pour le jésuites le cri universel fut prodigieux, mais il n'en fut autre chose.

Não obstante haver a história registrado fatos desse porte, é preciso dizer que a saúde dos alunos era muito bem cuidada nas maisons dos padres. Ao contrário de outras ordens, os jesuítas não partilhavam da ideologia segundo a qual "on travaille pour l'âme en mortifiant le corps", ao contrário, a Companhia tinha por princípio cuidar muito bem da saúde dos internos, mas defendia o uso moderado do fouet. Nas Constitutions se lê: "Servons-nous de petites ficelles qui blessent la peau, en effeurant l'extérieur, sans atteindre l'intérieur, pour ne pas nuire à la sante’".

O rigor com a disciplina se estendia ao método de ensino. A base da educação jesuítica era o ensino das línguas clássicas, grego, hebraico e latim, mas com ênfase nessa última, já que o objetivo era o de que os alunos falassem e escrevessem em latim. Por isso, nas primeiras versões do Ratio, a língua vulgar era de uso proibido até mesmo na conversação pessoal e privada entre os estudantes, salvo para os novos alunos que ainda não conheciam essa língua. A permissão para o uso do vernáculo, entre os alunos da classe intermediária para cima, era somente para os dias de festa, visando, antes de tudo, a recompensar o jovem pelo esforço despendido com os estudos, e, também, para que ele se sentisse mais confortável, como se estivesse em casa.

Somente no final do século XVII, quando os vernáculos já estavam gramatizados e consolidados, abriu-se o acesso ao seu uso nas classes. Segundo Compayré (op. cit., p. 186), na França, a influência da Grammaire de Port Royal foi decisiva para a mudança de posição dos jesuítas quanto a essa questão. $\mathrm{O}$

22 Apud Compayré, p. 179. 
vernáculo passou a ser usado na explicação das regras que, contudo, eram escritas nas línguas de origem, e a explicação sobre textos de autores gregos e latinos continuaram, durante muito tempo, a ser dada em latim.

Aqueles que elogiam o trabalho dos jesuítas, e mesmo alguns que o criticam, admitem que o esforço dos padres da Companhia, no que se refere ao ensino e aprendizagem do latim, chegava aos resultados desejados, tendo em vista que, em geral, o estudante aprendia essa língua. O problema, como se percebe nos comentários dos críticos, era o próprio método de ensino, penoso, difícil e demorado para o jovem estudante, que tinha de decorar uma infinidade de regras.

Quanto à ordem dos estudos, sabe-se que

la philosophie et les sciences occuppe [occupaient] les deux ou trois dernières années d'études. Mais la rhétorique est [était] le véritable couronnement des cours. C'est [c'était] en rhétorique que se produit [produisaient] dans tout son éclat l'élève des jésuites, c'est [c'était] lá qu'il se révèle [révèlaient] comme orateur latin, après s'être manifesté comme poète dans la classe d'humanités. Avant d'arriver en rhétorique, l'écolier a passé [passait] par quatre classes préparatoires, trois années de grammaire, et une classe d'humanités qui correspond [correspondait] à nos deux classes de troisième et de seconde. En cinq années, le cycle des études purement littéraires est [était] parcouru. (Compayré, p. 184)

Quanto às três classes de gramática, o Ratio Studiorum previa uma hierarquia de três níveis: suprema, media et infima classis grammaticae e o manual recomendado para uso do professor e do aluno em tais classes foi sempre o do português Manuel Alvares, De Institutione Grammatica libri tres (1572). Lê-se no próprio texto do Ratio Studiorum a seguinte recomendação: ${ }^{23}$

Gramática do P. Álvares - Cuide que os nossos professores adotem gramática do P. Manuel [Álvares]. Se em algum lugar o seu método parecer muito elevado para a capacidade dos alunos, adote então a gramática romana, ou, após consulta do Geral, mande compor outra semelhante, conservando sempre, porém, a importância e propriedade de todas as regras do P. Álvares.

23 Cf. http://dererummundi.blogspot.com/2010/01/ratio-studiorum-dos-jesuitas.html 
O primeiro livro, para a classe inferior, abrangerá o $1^{\circ}$ livro do P. Alvarez e uma breve introdução à sintaxe tirada do segundo.

O segundo livro, para a classe média, compreenderá o livro segundo do P. Alvarez sobre a construção das oito partes do discurso até as figuras e alguns apêndices mais fáceis.

O terceiro livro, para a classe superior, abraçará do livro segundo os apêndices mais elevados e da construção figurada até ao fim e o livro terceiro sobre a medida das sílabas.

O método empregado para a fixação das regras da gramática era o da repetição e da decoração e, ainda, exercícios escritos e composição, que os alunos faziam todos os dias da semana, exceto aos sábados. Para leitura, interpretação e, também, para subsidiar os exercícios escritos, os três níveis das classes tinham textos de dificuldades diferentes, embora dos mesmos autores, do seguinte modo: ${ }^{24}$

\section{Classe superior:}

Quanto às leituras, poderão explicar-se no primeiro semestre dos prosadores, as cartas mais importantes de Cícero aos parentes, a Ático, ao irmão Quinto; no segundo, o 1ivro da Amizade, da Velhice, os Paradoxos e outros assim; dos poetas no primeiro semestre algumas elegias ou epístolas de Ovídio, escolhidas e expurgadas, no segundo, trechos, também escolhidos e expurgados, de Catulo, Tibulio, Propércio e das Éclogas de Virgílio, ou ainda, do mesmo Virgílio, os livros mais fáceis como o 4o. das Geórgicas, o 5o. e o 7o. da Eneida; dos autores gregos, S. João Crisóstomo, Esopo, Agapetos e outros semelhantes.

\section{Classe média;}

Nas preleções só se usem as epístolas familiares de Cícero, algumas poesias muito fáceis de Ovídio e, no segundo semestre, se o Prefeito julgar conveniente, o Catecismo grego e a tábula de Cebes.

Classe inferior:

O objetivo desta classe é o conhecimento perfeito dos elementos da gramática, e inicial da sintaxe. Começa com as declinações e vai até a construção comum dos verbos. Onde houver duas subdivisões, na subdivisão inferior se explicarão, do primeiro livro, os nomes, verbos, as regras fundamentais, as quatorze regras da construção, os gêneros 
dos nomes; na superior do primeiro livro a declinação dos nomes sem os apêndices, e ainda os pretéritos e os supinos; do livro segundo, a introdução à sintaxe sem os apêndices até aos verbos impessoais. Em grego, a subdivisão mais atrasada aprenderá a ler e escrever, a mais adiantada os nomes simples, o verbo substantivo e o verbo barítono. Nas preleções adotem-se, dentre as cartas de Cícero, só as mais fáceis, escolhidas para este fim, e, se possível, impressas separadamente.

A gramática do Pe. Manuel Álvares foi, assim, utilizada no mundo Português (Portugal e suas colônias) durante 160 anos, se contados a partir da redação final do Ratio Studiorum, em 1599, e 173 anos, se contado o período da primeira recomendação, em 1586, época da elaboração, experimentação e revisão do Ratio. A gramática do Pe. Manuel Álvares circulou por todos os lugares em que havia penetração dos jesuítas. Somente para informar a grandeza dos números que envolvem as edições dessa obra, reproduzimos uma nota em que Cardoso (1995, p. 159, nota 3) informa o seguinte:

O Pe. Emilio Springethi, no estudo Gloria e Fortuna della Grammatica di Emmanuel Alvares, in "Humanitas" (volumes XIII e XIV), indica, baseado em Sommervogel, 530 edições em 22 países, ‘incluindo o México, a China e o Japão, fora da Europa (...) Na Itália contaram-se [mais de] 100 edições, na Bélgica, 73, na Checoslováquia, 71, Polônia com igual número e Portugal, 25'. Cf op. cit, p. XV

A gramática de Manuel Álvares caiu em desuso junto com a interdição dos jesuítas, e em 1759, quando foi promulgado o Alvará régio, de 28 de junho de 1759, todas as Escolas reguladas pelo método dos Jesuítas foram extintas e se estabeleceu um novo regime.

Esse Alvará foi concebido por Sebastião José de Carvalho e Melo, primeiro conde de Oeiras e marquês de Pombal, secretário de Estado do reino de Portugal no período do rei D. José I (1750-1777). O marquês de Pombal é considerado um dos intelectuais estrangeirados de Portugal, pois exerceu na Inglaterra (Londres) e na Áustria (Viena) a carreira diplomática, quando foi embaixador de Portugal de 1738 a 1749. Em 1750 foi nomeado secretário de Estado pelo rei D. José I. O Marquês de Pombal tendo, de um lado, conhecido o desenvolvimento econômico dos países onde viveu e, de outro, conhecido a 
realidade econômica de outros países europeus, reconhecia a situação de atraso de Portugal, onde ainda predominavam no campo das ciências, da economia e da religião ideias medievais. Conforme se diz na literatura histórica, Pombal foi um "representante do despotismo esclarecido", já que viveu sob a influência dos ideais iluministas e, a seu modo (e com muito exagero), os aplicou na reforma de seu país. Desse contexto resultou a reforma do ensino português, iniciada pelo referido alvará com a expulsão dos jesuítas. A justificativa que se tem dado para esse ato é a de que os objetivos do Estado haviam deixado de ser a fé e passado a ser a economia, para que, pela ciência e pelos estudos, Portugal pudesse sair do obscurantismo medievalesco em que se encontrava.

Nesse mesmo Alvará, no item “dos professores de gramática latina”, proibiu-se o uso da gramática de Álvares, e o rei determinou que fossem usadas gramáticas de padres oratorianos, como se lê no artigo sétimo: ${ }^{25}$

7. Nem nas ditas Classes, nem em outras algumas destes Reinos, que estejão estabelecidas, ou se estabelecerem daqui em diante, se ensinará por outro Methodo, que não seja o Novo Methodo da Grammatica Latina, reduzido a Compendio para uso das Escolas da Congregação do Oratorio, composto por Antonio Pereira da mesma Congregação: ou a Arte da Grammatica Latina reformada por Antonio Felix Mendes, Professor em Lisboa. Hey por prohibida para o ensino das Escolas a Arte de Manoel Alvares, como aquella, que contribuío mais para fazer difficultozo o estudo da Latinidade nestes Reinos. E todo aquelle, que usar na sua Escola da dita Arte, ou de qualquer outra, que não sejão as duas acima referidas, sem preceder especial, e immediata licença minha, será logo prezo para ser castigado ao meu Real arbitrio, e não poderá mais abrir Classe nestes Reinos, e seus Dominios.

A história da gramática latina de Manuel Álvares revela tanto muitas vozes que lhe são favoráveis quanto outras que lhe são contrárias. Conforme diz Cardoso (1995), a gramática alvarista tem o mérito de reunir o usus - considerando o latim praticado nas universidades, já que essa língua não era a tal altura uma língua natural de comunicação - e a ratio, essa "fundamentada na filosofia que investiga 'os princípios reguladores, os vera principia capazes de

25 http://dererummundi.blogspot.com/2010/01/ratio-studiorum-dos-jesuitas.html 
sustentar toda a gama de construções reunidas nos textos', ${ }^{26}$ e que, portanto, configura um instrumento que é ao mesmo tempo descritivo e racional.

A oposição à gramática alvarista baseia-se, principalmente, na complexidade e no exagero de suas regras e das glosas que recebeu quando foi reformada após a morte do autor. Para a sintaxe dos substantivos, por exemplo, há 247 regras. ${ }^{27}$ Para além do próprio texto, a crítica é feita ao método pelo qual se dá o ensino da gramática.

Neste trabalho, privilegia-se um dos mais importantes opositores da gramática e do método jesuítico para o ensino de gramática, Amaro de Roboredo. ${ }^{28} \mathrm{~A}$ importância que se lhe atribui justifica-se por meio de dois argumentos: primeiro, porque, mesmo em marcha lenta, a denúncia dos pontos negativos que enxergou no método de ensino ${ }^{29}$ frutificou, porque alguns autores ${ }^{30} \mathrm{co}^{-}$ meçaram a traduzir para o português as lições da De institutione grammatica libri tres, produzindo, assim, um novo gênero de instumento linguístico denominado na época como "cartapácio"; segundo, porque foi a partir dessa denúncia e da publicação de um método para ensinar a língua latina, que não somente era escrito em português mas também trazia estudo das especificidades gramaticais dessa língua, que a produção de instrumentos linguísticos portugueses começou a ser feita em vernáculo. ${ }^{31}$

26 O autor cita Lozzano Guilén, Carmen. La aportación gramatical renascentista a la luz de la tradición. Universidad de Valladolid, 1992. p. 33 ss.

27 Cf. Oliveira (1998, p. 4).

28 No século XVIII, Luís António Verney, autor do Verdadeiro método de estudar, publicado em Portugal, no ano de 1746, foi outro grande opositor da gramática do Pe. Manuel Álvares. Essa foi, inclusive, a obra que constituiu a base da reforma educacional do Marquês de Pombal.

29 Método cujo princípio era o de ensinar, a estudantes ignorantes dos princípios de gramática, a língua alvo (latim) pela língua materna (português), sendo que aquela já não era língua em uso corrente.

30 Um deles foi Bartolomeu Rodrigues Chorro em suas Curiosas advertencias da boa grammatica no compendio e exposiçaõ do P. Manuel Alvares, publicadas em Lisboa, no mesmo ano em que saiu o Methodo de Roboredo, 1619. Segundo expõe Romeo (2001, p. 320), esse foi o primeiro comentário à gramática do Pe. Manuel Álvares, em língua portuguesa.

31 Em 1610, Pedro Sanches escreveu uma gramática latina em português, a Arte de grammatica para em breve saber latim, que ficou muito tempo desaparecida, mas foi recentemente localizada e reeditada por León, R. P. de; Fernandes, G.; Assunção, C. C. (2007). 
As denúncias feitas por Roboredo em 1615, 1619 e 1623 acerca da falha do ensino (e da aprendizagem) decorrente do fato de a gramática latina ser escrita em latim, quando era destinada a um público jovem, que desconhecia não somente a gramática da língua latina mas também a de sua própria língua materna, não levaram as autoridades a promover alterações na metodologia do ensino de línguas. Essas mudanças desejadas por Roboredo somente vieram a ser implementadas com as reformas pombalinas, baseadas no Verdadeiro método de estudar, de Luís Antônio Verney (1746). Essa obra de Verney, por sua vez, é fundamentada na ideias de Roboredo.

O registro histórico das ideias linguísticas revela que o avanço representado pelo trabalho de Roboredo não foi reconhecido, senão cento e vinte e sete anos depois da publicação de sua obra, especificamente do Methodo grammatical para todas as linguas, em que não somente aplicou a metodologia revolucionária para a época como também a explicou pormenorizadamete no prefácio. Pelo aproveitamento da lição de Roboredo, feito por Verney, embora sem lhe dar o devido crédito, ${ }^{32}$ o ensino do latim foi radicalmente reformado, pois passou a ser feito com base na metaliguagem portuguesa, e o português passou a ser ensinado nas escolas, a partir de 1770, pela gramática Arte da gramática portuguesa, de Antonio José dos Reis Lobato, gramática oficial da reforma educacional promovida por Pombal. Pode-se, pois, dizer que a consequência da obra de Roboredo, não somente do Methodo, mas especialmente dele, pôde ser sentida efetivamente cento e quarenta anos depois de sua publicação, em 1619.

\subsection{O Methodo grammatical para todas as linguas}

O Methodo, como o próprio nome indica, antecipa a tendência universalista de tratamento da linguagem, inaugurada oficialmente pela Grammmaire gènerale et raisonée de Port Royal (1660). ${ }^{33}$ Roboredo parte da hipótese de que as línguas têm regras comuns e que, portanto, o aluno poderia aprender o latim pelo português, por isso aplica a metalinguagem portuguesa em seu método

\footnotetext{
32 Cf. Leite (2010).

33 Disse Lancelot: “O compromisso com que me empenhei, mais por acaso do que por escolha própria, de trabalhar nas gramáticas de diversas línguas, muitas vezes me levou a buscar as razões de várias coisas que são comuns a todas as línguas, ou particulares a algumas delas (...)." (Cf. Arnauld e Lancelot, 1992 [1660], prefácio).
} 
para ensinar latim. A ideia de que o latim era "a" língua universal, mais perfeita que todas as demais, começa a se desfazer depois do trabalho de Roboredo. Os gramáticos de séculos anteriores, Nebrija, quatrocentista, na Espanha, Fernão de Oliveira e João de Barros, quinhentistas, em Portugal, já defendiam o princípio universalista quando afirmavam que a aprendizagem da língua materna facilitaria a do latim, pois havia regras comuns a ambas as línguas, embora as houvesse também diferentes. Nebrija e João de Barros, porém, escreveram suas gramáticas latinas em latim e não na língua vernácula. Roboredo foi, mesmo, o pioneiro nesse método, tanto que, no prólogo da obra, explica:

Fica logo clara a obrigação do Artifice, quero dizer minha neste Methodo de me accommodar aa rudeza pueril, screvendo o na lingua Materna do principiante, levandoo per exemplos claros, \& ainda corporaes della para a Latina: que he a primeira raiz, que acima disse: $A$ notis ad ignota procedendum est. E fica clara a obrigação de dispor a materia ainda da lingua Materna segundo a natureza do discurso humano depēdēte dos sētidos: q he a segũda raiz: A facilioribus incipiendum est in tradendis artibus; ajuntando muitos exemplos em o livro, \& em voz, que o aprendiz veja, ouça, apalpe.

Desta obrigação do Artifice nasce outra ao executor do artificio: que he declarar primeiro as Declinações, Conjugações, \& Orações na lingua Materna do ouvinte, tocando a seu tempo a correspondencia da lingua, que ha de aprender, tocando sua conveniencia, \& differença, pois vão emparelhadas: \& isso com muita repetição de exemplos, \& das mesmas regras, pelas mesmas palavras, \& modo, porque, Obscurum est quod multipliciter dicitur: segundo a terceira raiz: Ex multis actibus fit habitus. $\mathrm{E}$ o que explicar no livro latino traduzirá o ouvinte na sua Materna, cuja frase irá assi aprendendo, exercitando a pena, \& Ortographia, notando a differença, \& conveniencia de amabs as linguas. (Roboredo, p. b2 [20])

A obra organiza-se em partes, livros e capítulos, como o autor expõe no "mostrador", ou sumário. O prólogo, acima citado, traz esclarecimentos sobre o método elaborado pelo autor e, no sumário, assim o autor o resume:

No prologo se toca hũa succinta apologia: em que lingua se devem screver as Grammaticas: que respeito ha de ter quem as faz, \& quem as ensina: a importancia de se eregir escola da Materna: o motivo, \& traça 
desta arte: como ficará universal: as condições do discipulo: os efeitos, que se vão mostrando. (Roboredo, p. ๆ 3)

A primeira parte é um "Exemplo português e latino da gramática", composta de três livros: I. o primeiro livro, "Da explicação compositiva das partes da oração Portuguêsa, \& Latina”, desdobra-se em cinco capítulos em que se estuda, comparativamente, o sistema, para usar um termo da linguística moderna, das duas línguas, a partir dos nomes (declinações e concordãncia do substantivo com o adjetivo); preposições (regência dos casos acusativo, abalativo e acusativo e ablativo); verbo (conjugações e concordância); II. O segundo livro trata "Dos nomes, \& Verbos irregulares, \& defectivos Latinos, \& algũs Portugueses correspondentes", organiza-se em quatro capítulos em que se estudam irregularidades das declinações, de nomes irregulares, dos comparativos e superlativos irregulares e verbos defectivos e irregulares; III. O terceiro livro trata "Da universal explicação resolutiva, \& compositiva das partes da Oração exemplificada na Lingua Latina", em que o autor mais se aproxima do modelo clássico da gramática, partindo da explicação do conceito de gramática, apresentando as partes da oração (cinco: nome, verbo, preposição, advérbio e conjunção) e seus acidentes (variação em gênero e número, composição e derivação de palavras, concordância e regência nominal e verbal, conjugação verbal).

A segunda parte é um "Exemplo Latino da copia de palavras", no qual o autor traz mil e duzentas frases latinas, sendo mil cento e quarenta e uma colhidas do Ianua Linguarum, e as restantes, cinquenta e nove, acrescentadas pelo autor. Às frases, o autor faz preceder a explicação de como o mestre deve explorá-las.

A terceira parte é um "Exemplo Latino de frase", colhido de autores clássicos, em que o gramático explora a sintaxe latina comparando-a com a portuguesa. Esse livro tem cinco capítulos, em que Roboredo faz preleções gramaticais, nos capítulos um a três, e, depois, no capítulo quatro, apresenta cento e oitenta e sete frases latinas, com a tradução em português. O quinto e último capítulo traz uma análise contrastiva de certos aspectos das duas línguas e é intitulado "De algũas propriedades da Frase Latina, \& Portuguesa entre si repugnantes". Constam também desse capítulo aspectos retóricos, como solecismo e barbarismo, fonéticos/fonológicos (quantidade da sílaba e acento) e estilísticos (figuras do verso) em relação ao latim. O Methodo é encerrado com um índice de adjetivos e verbos usados nos exemplos da segunda parte do livro. 
O desenvolvimento gramatical é sustentado em uma teoria "quinaria" da língua, afirmada desde o índice, ou mostrador da matéria do método, na parte 3, quando diz: "propoemse as raízes, de que depende a Frase pelo numero quinario, a que o Methodo tem respeito" (grifamos). ${ }^{34}$ Esse é, também, o número das classes de palavras (partes do discurso): ${ }^{35} 1$. Nome; 2. Preposição; 3. Verbo; 4. Advérbio; e 5. Conjunção. Também, a gramática é dividida em cinco partes, que englobam: 1. a variação (declinação e a conjugação); 2. a composição; 3. a derivação; 4. a concordância; e 5. a regência.

O Methodo grammatical para todas as linguas é, efetivamente, um manual para o ensino da língua latina, por meio da língua materna, que, nesse caso, é a portuguesa. Como o aluno precisa dominar a metalinguagem e a gramática portuguesa para aprender latim, o Autor termina embutindo na gramática latina uma teorização sobre o português, que aparece no Mostrador (sumário) com o título "ao curioso português". Além disso, a comparação das duas línguas revela algumas diferenças da portuguesa frente à latina, o que o autor descreve, creditando tudo ao uso. Disso decorrem os princípios teórico-metodológicos do Methodo, que se resumem nos seguintes pontos:

- Não se aprende uma língua desconhecida se a explicação de seu funcionamento se dá por meio dela mesma.

- A língua materna, pela facilidade de uso, é o meio mais eficaz para que as explicações das regras de funcionamento de uma língua desconhecida sejam compreendidas e assimiladas.

- A aprendizagem de uma língua por outra é viável porque há regras universais a todas as línguas.

- Uma língua tem, além de regras universais, particularidades, que advêm pelo uso, que devem ser reconhecidas pelo aprendiz.

- As regras da língua materna devem ser conscientemente conhecidas para que, por comparação, as regras da língua desconhecida sejam explicadas, compreendidas e assimiladas.

\footnotetext{
34 Na gramática alvarista, são oito as partes do discurso estudadas.

35 Os nomes englobam os substantivos e os adjetivos. Os substantivos dividem-se em comuns e próprios e os adjetivos em: pronomes demonstrativos; pronomes interrogativos; pronomes indefinidos (partitivos); pronomes possessivos; pronome relativo; numerais; graus do adjetivo (positivo, comparativo e superlativo); particípio.
} 
- O ensino e a aprendizagem da língua estrangeira se dão por comparação das duas gramáticas.

- As regras das duas línguas devem ser repetidas e memorizadas pelo aluno.

- As frases que servem de base para a aprendizagem da língua estrangeira devem ser estudadas em todos os níveis (ortográfico, léxico-semântico e sintático) e memorizadas.

- A técnica de aprendizagem da língua estrangeira é a tradução.

O tratamento que Roboredo faz da gramática portuguesa acaba revelando aspectos caracterizadores, e diferenciadores, importantes do português frente ao latim e, em certa medida, a outras línguas, já que a eleição de "regras universais" vai-se fazendo comparativamente, como se passará a ver.

\section{Aspectos sobre norma e uso no Methodo}

A obra de Roboredo, como já deve ter ficado claro, não é propriamente uma "gramática", no sentido mais tradicional da palavra. É um método de ensino de gramática que articula a língua materna e a língua estrangeira, sendo esta a língua alvo do ensino. Como o autor considerou que naquela altura do século XVII ainda não havia acontecido, efetivamente, a gramatização da língua portuguesa, teceu, primeiro, as regras do português, para, em seguida, levar o aluno a compreender, por essas, as do latim. Disso decorre o nosso interesse por essa obra, pois o autor, embora interessado nas regras comuns ao português e ao latim, não pôde passar ao largo de peculiaridades do português, de idiotismos como se dizia, a que se referia em partes dos capítulos reservadas "ao curioso português", o que constitui uma fonte preciosa para o conhecimento do uso e da norma da língua portuguesa praticada na época.

A seguir, examinaremos aspectos do Methodo em que há referências sobre uso e norma do português.

\subsection{A ordem das palavras}

Um dos pontos diferenciadores das duas línguas estudadas pelo autor é a ordem das palavras na frase. Embora Roboredo não contemple a ordem 
como característica organizadora da gramática, reporta-se, sem dar explicações, a uma "ordem direita", logo na primeira parte da obra, no livro I, capítulo V, quando fala "Da Composição Portuguesa \& Latina correspondentes, em que se encerra a sintaxe das outras artes". No início do capítulo, aparece o comentário sobre a existência do artigo na língua portuguesa, assim como na grega, e sobre sua inexistência no latim, quando anteposto ao nome, mas, quando posposto, teria a função de [pronome] relativo, caso em que a disposição da palavra na frase seria responsável pela nova função [classe/função], mas, nessa situação, o autor reconhece a identidade com o latim. Assim é a explicação:

A este articulo, O, A, que mostra o genero dos Sustantivos commũs, a modo da Grega, não responde a Latina com letra algũa; porem quando se pospõi he Relativo, a que responde a Latina com Is, Ille, \&c. como o tempo tira a tristeza consumindo a: Tempus adimit moestitiā, eam consumens, vel consumendo. (Roboredo, p. 47)

Mesmo sendo a ordem um aspecto diferenciador do português em relação ao latim (ou vice-versa), Roboredo vê alguma identidade quanto a isso, entre as duas línguas, pois diz que a oração portuguesa é iniciada pelo nominativo, como é comum a muitas orações do latim. Isso, contudo, não é claro na lição do gramático, porque ele diz também que, sobre o lugar das palavras na frase, não há regra, e que é o uso que orienta o falante:

A composição das partes da Oração, começa per Nominativo, \& consta de concordia antes da palavra, de regencia depois da palavra regente, $\boldsymbol{\&}$ do sitio dellas, que o uso ensina. (Ib.) (Grifamos)

A referência à "ordem direita" vem logo depois desses trechos, quando o autor passa a explicar a regência de algumas preposições:

As regencias principaes mostrão as preposições De, A. De, rege Genit. quando per ordem direita vai entre dous Sustantivos; \& o primeiro se une com o segundo q fica possuidor do primeiro: \& rege Ablativo; quando significamos separação ou composição. (Ib.) (Grifamos)

Ainda à "ordem direita" recorre Roboredo quando trata da sintaxe figurada, na primeira parte, livro III, capítulo IV. Nesse livro, o autor apresenta o que entende como regras universais de sintaxe, exemplificando-as com o 
latim, por isso o título do livro terceiro é "Da universal resolutiva, \& compositiva das partes da Oração exemplificada na língua Latina”. As regras a seguir apresentadas fazem parte do capítulo intitulado "Da Composição figurada":

Se se trocar a direita ordem da Composição se diz Anastrophe: ut mecum, tecu, quibuscum \&c.

(...)

Se a dereita ordem for mais confundida, se diz Synchesis; ut Brevis est magni fortuna favoris. (Roboredo, p. 76)

Outras referências quanto à ordem na língua latina e portuguesa aparecem quando o autor trata de estilo/retórica. Mesmo no latim, língua na qual, em tese, a ordem é flexível, vê-se que Roboredo fala, também, de uma "ordem mais natural", para dizer, talvez, mais usual e, sobre isso, no confronto das preferências de organização da frase, para o gramático e para o retórico, formula regras, como as que se podem ler no seguinte excerto, em que o autor trata de "Exemplo latino de frase", na terceira parte do Methodo, no capítulo III:

Da varia Frase, \& regencia de verbos, na qual se exercia a collocação rhetorica das palavras

Tres regras da collocação rhetorica.

As palavras da oração do Grammatico põi o Rhetorico em sitio quasi oposto. Porque o Grammatico segue a ordem natural, que mostrão os numeros, que vão sobre as sentēças da segunda parte deste Methodo. Porem o Rhetorico como pretende enfeitar esta Oração, collôca as palavras no sitio, que melhor armônia faz a orelha: \& nessa armônia consiste seu elegante ornamento, hora alongando, hora abbreviando, hora levando as palavras fora de sua propria significação. Sejão exemplos as regras seguintes.

1. Põe o Rhetorico no primeiro lugar o caso regido; no segundo, o Nominativo: no terceiro, o Verbo. E se o caso regido for negativo, o collôca no fim. Exemplo.

Grammatico. Virtus occupavit animam.

Rhetorico. Animam Virtus occupavit. 
Grammatico. Nullam animam cogito puriorem.

Rhetorico. Puriorem animam cogito nullam.

2. Põi o Rhetorico o Adjectivo primeiro, que o Sustantivo: \& entre ambos põi o Genitivo regido do Substantivo. Põi sempre o caso regido primeiro, que a palavra regente. Converte algũmas vezes o Genitivo em Adjectivo possessivo. Entre o Adjectivo, \& Sustantivo entremente algũma palavra ou palavras $\mathrm{O}$ Adverbio, \& Preposição com seu caso põi no lugar, que melhor armonia faz; mas principalmente antes de Verbo \& Adjectivo. Exemplo.

Grammatico. Virtus occupavit animam sanctissimam.

Rhetorico. Sanctissiman animam virtus occupavit.

Grammatico. Virtus occupavit animam sanctissiman Virginis.

Rhetorico. Sanctissimam Virginis animam occupavit. (...)

3. Ajunta o Rhetorico a hum Sustantivo dous Adjectivos: \& dous Sustantivos a hum Adjectivo, duplicando estas particulas, Tum, Cum; Et. E se na primeira parte da clausula, quer dizer menos, que na segunda, põi na primeira, Cum, \& na segunda Tum. Exemplo.

Intensissimis, \& precibus, \& laboribus Virgo illa tum humilis, tum prudens nobis, è Paternae mentis sinu divinu deduxit Redemptorem: quae mitificam cùm in proximos humanitatem, tùm in Deum religionem, omni tempore exercebat. (Roboredo, p. 203) (Grifamos)

Pelo trecho, depreende-se que a ordem mais comum (a "direita" ou "natural") é, no latim e no português, Nominativo + Verbo + Casos regidos, ou, como se diz hoje, SVO. O autor observa também a ordem do sintagma nominal, substantivo + adjetivo, que pode ser alterada e, ainda, que pode ter a adjacência rompida, pelo acréscimo de outros elementos entre ambos. A posição do advérbio é móvel, a depender do sentido que se almeja alcançar. O excerto a seguir traz outro comentário sobre a posição do advérbio em latim e em português.

No quinto capítulo da terceira parte do Methodo, ao confrontar o português e o latim, Roboredo faz uma observação sobre a disposição do verbo 
e do advérbio na frase, nas duas línguas e, então, afirma uma diferença entre ambas pela posição que algumas palavras ocupam na frase:

\section{Capitulo V.}

De algũmas propriedades da Frase Latina, \& Portuguesa entre si repugnantes.

\section{(...)}

8. Em sitio diverso assenta a Latina as palavras do que a Portuguêsa. Porque a Latina segundo a regra da elegancia põi o Verbo no fim da Oração pag. 203. \& a Portuguesa poucas vezes. E os adverbios quer a latina antes dos Verbos; \& a Portuguesa depois; isto pela maior parte: como, morreo voluntariamēte: sponte obijt. (Roboredo, p. 229)

A leitura do Methodo indica que a ordem das palavras na oração não foi, para Roboredo, categoria organizadora da gramática. Um dos conceitos de gramática que apresenta, todavia, incorpora a ordem como fator essencial, pois o autor parte da premissa de que "a arte de falar", ${ }^{36}$ que é a gramática, exige que a oração seja bem formulada, o que implica a organização (disposição, ordem) das palavras na frase, como se pode conferir abaixo:

Grammatica he arte de falar, que tem por fim a Oração bem concertada: a qual he hũa coherente disposição de palavras, de que consta, como partes. Procede para a Oração per Lettras, Syllabas, \& Declinações, ou Palavras. (Roboredo, p. 64)

O desdobramento do conceito, contudo, não recupera mais a ordem como categoria. Segundo o autor, a oração é formada de palavras, que tem cinco "gêneros": nome, preposição, verbo, advérbio e conjunção. A gramática, por sua vez, divide-se, também, em cinco partes, que são: 1. "variação", em que se estudam as flexões nominais e verbais; 2. em "derivação"; 3. em "composição";

36 Conceito de gramática que extraiu de Sanctius (1587) e se repete na Grammaire Générale et Raisonée de Port Royal (1660). 
4. em "concordância", nominal e verbal; e 5. em "regência", quanto ao nome, preposição, verbo e advérbio.

A ordem, como procuramos mostrar, surge em comentários esparsos e assistemáticos, ora apenas sobre a língua latina - compondo regra que se pretende universal - ora em regra sobre a língua portuguesa, em oposição à latina.

\subsection{A sintaxe de regência}

Na primeira parte do Methodo, livro I, cap. V, o autor dedica-se ao estudo da "sintaxe de regência", ou simplesmente, emprego das preposições, trabalhando comparativamente com as duas línguas, o que o fez chegar a conclusões que o levaram ao comentário posto no Mostrador: "Novas regras achadas e mostradas em uso".

Quando Roboredo trata diretamente da regência, pelo estudo particular do funcionamento das preposições portuguesas e de suas correspondências com as latinas, é possível observar claramente o procedimento de passagem de um língua a outra, como nestes trechos:

Na Portuguesa sempre o Genitivo he regido da Preposição, DE, que alem disso rege ablativo ; \&, A, rege Dativo, Accusativo, \& Ablativo ${ }^{37}$ pag 47-49. Pera rege tambem Dativo, Para, Accusativo : como Pera mim tenho, que de casa de teu pae saisse para a praça com intento de fazer mal a Pedro, \& se tirar a capa a Paulo, que se recolhia aa Igreja.

Assi como na Latina ha mais esses Adverbios ou Preposições, Circiter, Prope, Propius, Proxime, Secus, Vsq ; Versus, Versum ; que despois de si querem, Ad, com seu caso ; assi na Portuguesa ha estas, Abaixo, Ao redor, Dentro, Despois, Detrás, Junto, Diante, as quaes tem por caso outra Preposição com seu caso, como, Junto a Deus, Abaixo dos Anjos, Dentro na Gloria \&c.

Palam, he adverbio como tambem, Procul. E achando se Procul dubio, entendese, A, ut Procul a dubio. A, se usa antes de Consoante : Ab, antes de Vogal, Abs, antes de t q. ut A Pedro, \& ab omni homine ne dũ abs te discam. Todas tres significão separação, \& como de parte de alguem. (Roboredo,p. 12-13) (Grifamos)

37 Os grifos em negrito são nossos. 


\section{Quando a Preposição, De, rege Genitivo não lhe responde a Latina} cõ letra algũa, \& assi na Latina fica o Genit. de possuidor regido de Sustantivo possuido, como fica mostrado. (...) E quando se antepõi a pessoas que fica sendo Aquisição na Latina, que não responde com letra algũa a esta Preposição : como, convem ao Mestre : Convenit Magistro : \& algũas vezes se usa a pessoa em Accusativo, \& responde a latina com, Ad, como O que a mim me toca : Quod ad me attinet; ad te placebit : A ti te contentará. E tambem quãdo se antepõi a cousas grandes : Ad heroica aspirat : Põe a tranca aa porta : Obde pessulum portæ. [p. 48- 49] (grifamos)

Assim se vê caracterizada a norma portuguesa quanto ao uso das preposições nos genitivos, ou adjuntos restritivos (atributivos e possessivos), nos adjuntos circunstanciais e em locuções adverbiais e nos complementos verbais (dativos e certos acusativos). Em todos esses casos, a interpretação do uso, ou emprego, da preposição como questão de "ordem da palavra na frase" porque o autor faz a descrição das frases latina e portuguesa com base na observação dos elementos que se encontram adjacentes e, no que concerne ao artigo e à preposição isso tem especial relevo, porque são essas duas classes que fazem a ponte da declinação latina para a "declinação portuguesa".

A ordem das palavras, pois, embora não seja vista como aspecto categorial da gramática, representa importante ponto de referência para a comparação e diferenciação das línguas latinas e portuguesa, impondo-se como aspecto caracterizador das línguas.

\subsection{Particularidades dos verbos portugueses}

Quanto aos verbos, Roboredo observa que, em razão de a língua portuguesa não contar com formas específicas, simples, para traduzir a voz passiva latina e de outras línguas, desenvolve "rodeios", ou seja, formas combinadas com o verbo ser ou o pronome apassivador, como é denominado hoje, se, para expressá-la. Diz ele que: ${ }^{38}$

38 Destes mesmos exemplos servem-se Assunção; Gonçalves (2007, p. LXIII), com o objetivo de analisar a teoria de Roboredo quanto ao verbo. 
O Verbo, ou he Activo ou Passivo. Na Portuguesa não ha mais voz passiva, que o Participio, \& Gerúndio em, Do. (Roboredo, p. 13)

O assunto é retomado na sequência do texto, quando o Autor reafirma que:

$\mathrm{Na}$ Portuguesa em que não ha vozes passivas mais que o nome Participio em, Do, \& Gerundio indiclinavel, como Amado, Amando, usamos de rodeio feito deste Participio, \& do verbo, Sou ; como fica exemplificado nas passivas atras. Alem disso para suprirmos esta falta, \& interpretarmos os tempos de outras linguas, usamos hum rodeio de terceiras pessoas passivas feito das activas, \& do Accusativo, Se, como movia se, movera se, elle se movesse, mova se, \&c. Por este rodeio Se significa, ou o mesmo agente do verbo, que redobra sobre si, ou outro em commum, \& confuso, que corresponde aos Impessoaes dos Grammaticos ; como Affirmava se que vinheis a esta cidade. (Ibidem, p. 32)

e, depois, ainda volta ao assunto, quando explica :

Nas linguas vulgares, de que temos noticia, não ha Verbos Passivos : mas ha Participios Passivos, com os quaes, \& com o Verbo Sustantivo Sum, se suprem as Vozes Passivas ; como em Português : Amado, ajuntase ao Verbo, Sou, assim ; Sou amado ; Fui amado ; Serei amado \&c. Semelhantes rodeios se fazem com esses Acusativos Me, Te, Se, Nos, Vos, se, juntos aas vozes Activas ; como Movome, Movese, Movemosnos, Moveivos, Movemse ; \& assi mais tempos ; mas nas terceiras Pessoas, mais propriamente. (ib., p. 69)

Desse modo fica registrado no Methodo a descrição da vozpassiva verbal, na denominação atual, pelo uso que o povo português fez dos torneios, rodeios, como os descreveu Roboredo, que foram substituindo os verbos passivos latinos.

Também nesse exemplo se vê a referência ao verbo mover, acompanhado de pronome reflexivo, que compõe a voz reflexiva, fato inexistente no latim.

Uma particularidade da língua portuguesa que, pelo que se sabe, foi Roboredo o primeiro a gramatizar, diz respeito à conjugação verbal. Trata-se do uso do infinitivo flexionado, ou infinitivo pessoal, que ele assim descreve:

Tem finalmente a portuguesa hum Infinitivo que o uso corrompendoo fez pessoal \& dele carecem as linguas de que tenho notícia, Como eu 
amar, tu amares, elle amar. Pl. Nos amarmos, vos amardes, elles amarem ; he semelhante ao segundo futuro : mas em algũs verbos não, como eu dizer, tu dizeres, \& c. Eu fazer, tu fazeres, elle fazer : De nos fazermos arte Portuguesa resultará proveito na Republica.

Em 1721, Jerônimo Contador de Argote também se referiu ao infinitivo, mas essa particularidade do português só foi efetivamente estudada por outro Jerônimo, o Soares Barbosa, em obra de 1823.

\subsection{A norma do português frente a outras línguas}

No livro III, do capítulo 1, p. 64-68, cujo título é “ Tudo o mais para a inteira Grammatica Portuguesa [o leitor curioso] achará ", o Autor apresenta as " regras universais " para todas as línguas, mas faz comentários sobre as exceções de algumas línguas a essas regras, pontuando características da portuguesa, conforme se poderá ler a seguir alguns exemplos: ${ }^{39}$

Da Preposição

(...)

Em algũas linguas ha tambem Preposições, que regem Genitivo, \& Dativos ; como na Portuguesa, \& Grega ; mas na Latina regem soomene Accusativo, \&Ablativo. Em qualquer lingua he limitado o numero dellas. (p. 68)

Do Verbo

(...)

Nas linguas vulgares, de que temos noticia, não ha Verbos Passivos : mas ha Participios Passivos, com os quaes, \& com o Verbo Sustãtivo, Sum, se suprem as Vozes passivas ; como em Portugues Amado, ajuntase ao Verbo, Sou, assi ; Sou amado, Fui amado : Serei amado \&c. Semelhantes rodeios se fazem com esses accusativos (...). (p. 69)

Do Adverbio

Algũs Adverbios significão paixões de animo : outros tempo : outros lugar : outros varios accidentes. Hũs saõ Simples, outros compostos : hũs primitivos : 
outros derivados, que em cada lingua se vão notando. Na Portuguesa como saõ poucos os Simples usamos de compostos : dos quaes acabão em mente, como Altamente. (p. 70)

Da composição das cinquo partes da oração, que se fizer per Concordia, \& Regencia. As quatro concordias.

(...)

3. Os Atticos ajuntão algũas vezes a hum Nominativo neutro de Plural hũa terceira Pessoa singular : ut Templa erat ingentia : que he solecismo na Latina. Com outra semelhante irregularidade lhe responde a Portuguesa no Verbo Sou, \& Hei, havia diversas opiniões \&c. Eram opiniones diversas \&c. (p. 72')

Regencia dos Casos.

(...)

2. O genitivo na lingua Portuguesa, \& outras vulgares, sempre he regido de Preposição, De, expressa como, o Somno he imagem da morte : porem na latina sempre he regido de Nome Sustantivo : ut Sopor lethi imago. (p. 73)

Esses comentários, além de reafirmar a preocupação do autor com o uso e a norma portugueses, como vimos tentando mostrar, deixam claro como as demais línguas, vulgares e clássicas, compõem um quadro comparativo subliminar para a eleição de regras que se pretendem universais e para a fixação (ou pelo menos o reconhecimento) de outras que são próprias de cada uma delas, com especial relevo para o português.

\section{Considerações finais}

Em primeiro lugar, o que se observa pela análise de documentos históricos em que se pode analisar o desenvolvimento da gramaticografia portuguesa é que a lição de Roboredo, embora inovadora para o século XVII, não ecoou em Portugal no momento de sua publicação. Foi preciso esperar mais de cem anos para que a lição desse gramático fosse retomada, e o fundamento de seu método de ensino, aplicado, o que só veio a ocorrer pelo conhecimento da obra de Luís Antonio Verney, Verdadeiro Método de Estudar, no século XVIII. 
Diante de tudo o que se discutiu, pode-se dizer que a obra de Amaro de Roboredo e, especialmente, o Methodo grammatical para todas as línguas, surgiu no cenário educacional português motivada pela visão crítica que o gramático teve sobre a situação do ensino do latim em Portugal, o que se fazia pelo método jesuítico. A consequência tardia do trabalho do autor - já que ocorreu mais de cem anos depois da publicação de sua obra, com a publicação do Verdadeiro método de estudar, de Verney - para o cenário educacional em Portugal, e, por extensão, em suas colônias da época, foi não somente a renovação do ensino do latim mas a instauração do ensino do português nas escolas, instituído pelo Alvará Régio de 1759.

O Methodo foi também importante para o conhecimento da língua portuguesa, pois sendo a tese do autor a de que o aprendiz assimilaria rapidamente as regras do latim pela comparação dessas com as de sua língua, a sistematização do português foi imprescindível. Esse trabalho de gramatização da língua vernácula o levou ao reconhecimento de usos e normas próprios dessa língua (os idiotismos), fato importante para o conhecimento da norma de então e da reconstrução das ideias linguísticas e da representação que se tinha da língua.

Quanto ao registro de norma e uso do português, o que se fez especialmente na parte reservada aos leitores interessados em ampliar seus conhecimentos sobre a língua portuguesa, intitulada de modo muito original como " $A$ o curioso português", como já comentado. Ali se veem os temas aqui comentados, como o da ordem das palavras na frase, ou na "oração", como diz o autor. A ordem, colocação ou disposição das palavras na oração, como comentado, foi fator fundamental na argumentação do autor pelo estudo de alguns temas gramaticais, como artigo, verbo e advérbio.

Outros temas fundamentais para caracterizar o português, recorrentes na argumentação de Roboredo, foram o verbo, especialmente nas vozes passiva e reflexiva, e a preposição. Sobre aquele, uma observação importante de Roboredo referiu-se ao infinitivo flexionado, talvez a primeira observação sobre essa particularidade da língua. O emprego da preposição, sempre referido como casos de regência, é também fundamental, pois o autor ainda insiste na identidade de casos entre o latim e o português, o que se faria, nessa língua pelo uso de artigos (para o nominativo) e preposições (para genitivo, dativo e ablativo). 
O exame dessa obra é fundamental ao conhecimento das teorias linguísicas vigentes e produtivas em Portugal no século XVII, mesmo se, como é o caso de Roboredo, a teoria usada não tenha tido eco de imediato no país.

\section{Referências bibliográficas}

\section{Fonte}

- século XVII

ROBOREDO, Amaro (1619). Methodo grammatical para todas as linguas. Salamanca. Edição de Marina A. Kossarik. Lisboa: Imprensa Nacional - Casa da Moeda.

\section{Obras de Roboredo}

ROBOREDO, Amaro (1615). Verdadeira grammatica latina, para se bem saber em breve tempo, scritta na lingua portuguea com exemplos na latina. Edição facsimilada por FERNANDES, Gonçalo ; LEÓN, Rogelio Ponce de ; ASSUNÇÃO, Carlos (2007).

\section{Estudos}

ASSUNÇÃO, Carlos da Costa (1997). Gramática e gramatologia. Braga: APPACDM Distrital de Braga.

. Para uma gramatologia portuguesa: dos primórdios do gramaticalismo em Portugal a Reis Lobato. Vial Real: Universidade de Trás os Montes e Alto Douro.

ASSUNÇÃO, Carlos da Costa; FERNANDES, Gonçalo (2007). Prefácio e Estudo introdutório. In: ROBOREDO, Amaro (1619). Methodo grammatical para todas as linguas. Lisboa: Pedro Craesbeck. Edição facsimilada.

AUROUX, S. (Org.) (1992). Histoire des idées linguistiques (2) - Le développement de la grammaire occidentale. Liège-Bruxelles: Mardaga, t. 2, p. 107-114.

AUROUX, S. (1992a). A revolução tecnológica da gramatização. Trad. do francês por Eni Orlandi. Campinas, SP: UNICAMP.

. (1993). Remarques sur l'histoire philosofique du concept de "norme" et sur l'histoire des sciences du language. In: Jean-Michel Kasbarian (éd) et le Centre Dumarsais (Centre des sciences du langage). Genèse de la (des) norme(s) linguistiques. Actes de la 3ème Table ronde de L'Aprodelf, Aix - 18-19 juin.

- (1998). La raison, le langage et les normes. Paris, PUF.

- (2007). La question de l'origine des langues, suivi de L'bistoricité des sciences, Paris, PUF, collection Quadrige-Essais. 
ARNAULD, Antoine; LANCELOT, Claude (1997). Grammaire générale et raisonnée. Présentation de Jean-Marc Mandosio. Allia. [Le texte de cette édition reproduit celuit de la 3e édition de la Grammaire, datée de 1676]

ARNAULD, A.; LANCELOT, C. (1992). Gámática de Port-Royal. Tradução de Bruno Basseto e Henrique Muracho. São Paulo: Martins Fontes. [1660]

BARATIN, Marc. (1989). La naissance de la syntaxe à Rome. Paris: Minuit.

CARDOSO, Simão (1995). A gramática latina no séc. XVI. As "Partes orationes" na gramática do Pe. Manuel Álvares (1572) e na Minerva de Sanctius (1587). Revista da Faculdade de Letras 'Linguas e Literaturas'. Porto, XII, p. 159-172. Acessado em 17/04/2010 em www.ler.letras.up.pt/uploads/ficheiros/2703.pdf

COMPAYRE, Gabriel. Histoire critique des doctrines de l'éducation en France depuis le seizième siècle. 7ed. Paris: Hachette, 1904, t.1. Disponible sur BNF / Gallica.

COMPAYRE, Gabriel. Histoire critique des doctrines de l'éducation en France depuis le seizième siècle. 7ed. Paris: Hachette, 1904, t.2. Disponible sur BNF / Gallica.

FERNANDES, Gonçalo (2005). A Ianua Linguarum dos jesuítas irlandeses (Salamanca, 1611) e a Porta de Linguas de Amaro de Roboredo (Lisboa, 1623). Boletim de Estudos Clássicos, 42.

KOSSARIK, Marina (2002). A obra de Amaro de Roboredo : questões de historiografia linguística portuguesa. In: ROBOREDO, Amaro (1619). Methodo grammatical para todas as linguas. Salamanca. Edição de Marina A. Kossarik. Lisboa: Imprensa Nacional - Casa da Moeda.

LEITE, Marli Quadros (2007). O nascimento da gramática portuguesa - uso e norma. São Paulo: Humanitas/Paulistana.

(2010). Uma "teoria da tradução" no Methodo Grammatical para todas as linguas. In: Assunção, C.; Fernandes, G.; Loureiro, M. (eds.). Ideias linguisticas na Pensinnsula Ibérica. Münster: Nodus Publikationen, v. 2, p. 495-509.

LEÓN, R. P. de; ASSUNÇÃO, Carlos; FERNANDES; Gonçalo (2007). Pedro Sánchez - Arte de grammatica pêra em breve saber latim. Com prefácio de Amadeu Torres. Ed. Facsimilada. Vila Real: Centro de Estudos em Letras.

NEVES, Maria Helena de Moura (2002). A questão da ordem na gramática tradicional. In: CASTILHO, A. T. de (Org.). Gramática do português falado - a ordem. 4 ed. rev. Campinas: Ed. UNICAMP.

NISARD, Désiré. Etudes sur la Renaissance: Renaissance et réforme: Erasme, Thomas Morus, Mélanchton. 2ed. Paris: Michel Lévy, 1864. [Ressource électronique, 2002]. Disponible sur BNF / Gallica. 
OLIVEIRA, Luís Miguel (1998). Luís António Verney e o Verdadeiro Método de estudar. Um pensamento inovador entre Portugal e a Europa. Acessado em 17/04/2010 em http://www.ipv.pt/millenium/miguel11.htm (8 of 9) [17/4/2010 10:02:08]

ROMEO, Rogélio Ponce de Léon (2001). El Àlvarez en vernaculo: las exegesis de los de "Institutione grammatica libri tres" en Portugal durante el siglo XVII. Revista da Faculdade de Letras 'Línguas e Literaturas'. Porto, XVIII, p. 317-338. Acessado em 17/04/2010 em www.ler.letras.up.pt/uploads/ficheiros/

SANCTIUS (1587). Minerve ou les causes de la langue latine. Trad. e edit. de G. Clerico (1982). Lile: Presses Universitaires de Lile.

\section{Textos de autoria coletiva (sem indicação de autoria)}

De Rerum Natura - A Ratio Studiorum dos jesuitas. http://dererummundi.blogspot. com/2010/01/ratio-studiorum-dos-jesuitas.html

O método pedagógico dos jesuitas. A Ratio Studiorum. Traduzido pelo HISTEDBR - Grupo de Estudos e Pesquisas "História, Sociedade e Educação no Brasil". http://www. histedbr.fae.unicamp.br/navegando/fontes escritas/1 Jesuitico/ratio $\% 20$ studiorum. htm. Acessado em 16/04/2010.

Periodo jesuitico. http://www.pedagogiaemfoco.pro.br/heb02.htm.

Periodo Pombalino. http://www.pedagogiaemfoco.pro.br/heb03.htm.

Periodo Joanino. http://www.pedagogiaemfoco.pro.br/heb04.htm.

\section{Outros textos}

Érasme. Doze coloquios de Erasmo, Varon doctissimo y eloquentissimo. 1530.

Érasme. La civilité morale des enfans. Traduction française Claude Hardy. Paris: Jean Sara,1613.

Érasme (1469-1536). La Civilité puérile. Traduction nouvelle, texte latin en regard, précédée d'une notice sur les livres de civilité depuis le XVIe siècle, par Alcide Bonneau. Paris: Isidore Liseux, 1877.

Recebido em: 15/12/2010

Aprovado em: 17/05/2011 